\title{
Low copy number of FCGR3B is associated with lupus nephritis in a Chinese population
}

\author{
ZHAOHUI ZHENG $^{1 *}$, RUOHAN YU $^{1 *}$, CONGCONG GAO $^{1}$, XIANAN JIAN ${ }^{1}$, \\ SONGXIA QUAN ${ }^{2}$, GUOLAN XING ${ }^{2}$, SHENGYUN LIU ${ }^{1}$ and ZHANGSUO LIU ${ }^{2}$ \\ Departments of ${ }^{1}$ Rheumatology and ${ }^{2}$ Nephrology, The First Affiliated Hospital of \\ Zhengzhou University, Zhengzhou, Henan 450052, P.R. China
}

Received October 14, 2015; Accepted February 27, 2017

DOI: $10.3892 / \mathrm{etm} .2017 .5069$

\begin{abstract}
Lupus nephritis (LN) is a polygenic disease caused by an interaction between hereditary and environmental factors. Numerous gene copy number variations have been identified to contribute to this disease. Previously, immunoglobulin (Ig)G Fc $\gamma$ receptor 3B (FCGR3B) copy number variation (CNV) was reported to be associated with $\mathrm{LN}$ in the Caucasian population. However, the effect of FCGR3B CNV on LN in the Chinese population remains unknown. The present study aimed to investigate whether CNVs of FCGR3B are associated with LN in the Henan Chinese population. FCGR3B CNVs were determined in $142 \mathrm{LN}$ patients and 328 healthy controls. A modified methodology based on competitive polymerase chain reaction, a Multiplex AccuCopy ${ }^{\mathrm{TM}}$ kit was used to detect FCGR3B copy number. Clinical and laboratory data was collected retrospectively from medical records. To evaluate associations between FCGR3B CNVs and LN susceptibility, the present study calculated the odds ratios using a logistic regression analysis. The current study identified that the distribution of FCGR3B copy number was significantly different between LN and healthy controls $(\mathrm{P}=0.031)$. A low copy number $(<2)$ of FCGR3B was significantly enriched in $\mathrm{LN}$ patients $(\mathrm{P}=0.042)$, and was a risk factor for $\mathrm{LN}$ (odds ratio $=2.059$; $95 \%$ confidence interval, 1.081-3.921; $\mathrm{P}=0.028)$. However, a high copy number $(>2)$ had no effect on LN. There were no associations between FCGR3B $\mathrm{CNV}$ and clinical phenotypes of LN. The results from the present study demonstrate that a low copy number of FCGR3B is a risk factor for $\mathrm{LN}$ in a Chinese population.
\end{abstract}

Correspondence to: Professor Zhangsuo Liu, Department of Nephrology, The First Affiliated Hospital of Zhengzhou University, 1 Eastern Jianshe Road, Zhengzhou, Henan 450052, P.R. China E-mail: zhangsuoliu@sina.com

*Contributed equally

Key words: copy number variance, FCGR3B, lupus nephritis, systemic lupus erythematosus

\section{Introduction}

Systemic lupus erythematosus (SLE) is a complex autoimmune disease with diverse clinical manifestations, including constitutional symptoms, rash, mucosal ulcers, inflammatory polyarthritis, photosensitivity, serositis and certain life-threatening manifestations, such as lupus nephritis (LN) (1). The etiology of SLE involves multiple factors including genes, infections, sex hormones and environmental factors (2). Of these, genes serve the most important role. Numerous types of genetic variations contribute to the diversity of the human genome such as chromosomal translocations, variable number tandem repeats, inversions, single nucleotide polymorphism, copy number variations (CNVs) and insertions and deletions. During the past decade, CNVs have received substantial attention as a major performance of genetic diversity, covering $\sim 12 \%$ of the human genome (3). CNVs may arise either when a complete gene or gene segment had been duplicated or when a gene is abnormally absent. The CNVs of toll-like receptor 7, C-C chemokine ligand 3-like 1, complement component $\mathrm{C} 4$ and immunoglobulin (Ig)G Fc $\gamma$ receptor 3B (FCGR3B) have been most intensively studied in association with various autoimmune disorders (4-8). Fc $\gamma$ receptors $(\mathrm{Fc} \gamma \mathrm{Rs})$ mediate a variety of immune functions that are critical in immune responses, including immune complex clearance, phagocytosis, antigen presentation, antibody-dependent cellular cytotoxicity and cytokine production (9). In humans, five different Fc $\gamma$ Rs have been identified: Three FCGR2 genes (FCGR2A, FCGR2B and FCGR2C) and two FCGR3 genes (FCGR3A and FCGR3B) (10). Amongst these, an association between FCGR3B and a risk of autoimmunity has been the most intensively investigated to date. FCGR3B copy number deficiency is associated with a number of different autoimmune diseases, including SLE (11-15), Sjogren's syndrome (16) and systemic sclerosis (17). Although a low FCGR3B copy number is reportedly associated with SLE susceptibility in Afro-Caribbean and Caucasian populations, to the best of our knowledge, no information is available regarding the Henan population in China. The relationship of FCGR3B copy number with $\mathrm{LN}$, the most common life-threatening manifestation of SLE (18), has also not been studied in this population. To further study the pathogenesis and genetic basis of $\mathrm{LN}$ in the Henan population, the present study assessed the FCGR3B 
copy number and investigated whether FCGR3B CNVs were associated with susceptibility to LN.

\section{Patients and methods}

Patients. The current study comprised 328 healthy control individuals recruited from the Physical Examination Center in the First Affiliated Hospital of Zhengzhou University (Zhengzhou, China) between January 2012 and December 2013. The age of the healthy control individuals was $31.96 \pm 11.69$ years (mean \pm standard deviation) and the group consisted of 298 females and 30 males (9.93:1). The weight of healthy controls was $45.5-75.0 \mathrm{~kg}$. A total of 142 Henan patients with LN who fulfilled the 1997 revised criteria for the classification of SLE (19) were recruited at the First Affiliated Hospital of Zhengzhou University between January 2010 and March 2013. The age of patients with LN was $29.34 \pm 10.72$ years (mean \pm standard deviation) and the group consisted of 130 females and 12 males (10.83:1). The weight of LN patients was 44.0-78.5 kg. Diagnosis of LN was established according to the American College of Rheumatology criteria: 24 -h proteinuria $>0.5 \mathrm{~g}$ or a spot urine protein/creatinine ratio of $>0.5$; proteinuria $>3$; cellular casts including red blood cells, hemoglobin, granular, tubular or mixed $(20,21)$. All patients with LN were confirmed by renal biopsy in the First Affiliated Hospital of Zhengzhou University between January 2010 and March 2013. Cases and controls were matched for age and gender. The current study was approved by the Ethics Committee of the First Affiliated Hospital of Zhengzhou University, and all participants provided written informed consent.

Data collection. Information pertaining to demographic characteristics, clinical and laboratory data were collected retrospectively from medical records. Pathological phenotype was assessed according to the revised International Society of Nephrology/Renal Pathology Society (22). Activity index (AI) and chronic index (CI) score were calculated by two renal pathologists (23). The systemic lupus erythematosis disease activity index (SLEDAI) score for each patient was calculated at the time of renal biopsy (24). The laboratory data, including blood, urine, antibody and complement test results, were routinely assessed in the Department of Laboratory Medicine of the First Affiliated Hospital of Zhengzhou University.

Genotyping. Peripheral blood was collected at the time of renal biopsy. Genomic DNA was extracted from peripheral blood using a Gentra Puregene Blood Core Kit C (Qiagen, Inc., Valencia, CA, USA) following the manufacturer's protocol. The primers for target segments were obtained from the GenBank database (www.ncbi.nlm.nih.gov/genbank) (Table I). The copy numbers of FCGR3B were measured by a custom-by-design Multiplex AccuCopy kit (Genesky Biotech Co., Ltd., Shanghai, China) based on a multiplex fluorescence competitive polymerase chain reaction (PCR) principle as described previously (25). Data was produced according to the manufacturer's protocol. Briefly, a $20 \mu 1$ PCR reaction was prepared for each sample, containing: 1X Multiplex PCR Master Mix (Genesky Biotech Co., Ltd.), 1X Competitive DNA mix (Genesky Biotech Co.,
Ltd.), $1 \mu$ l Fluorescence Primer Mix (Sangon Biotech Co., Ltd., Shanghai, China) and $10 \mathrm{ng}$ sample DNA. The PCR program was completed as follows: $95^{\circ} \mathrm{C}$ for $10 \mathrm{~min}$; 11 cycles $\mathrm{x}\left(94^{\circ} \mathrm{C}\right.$ for $20 \mathrm{sec} ; 65^{\circ} \mathrm{C}-0.5^{\circ} \mathrm{C} /$ cycle for $40 \mathrm{sec} ; 72^{\circ} \mathrm{C}$ for $\left.1.5 \mathrm{~min}\right) ; 24$ cycles $\mathrm{x}\left(94^{\circ} \mathrm{C}\right.$ for $20 \mathrm{sec} ; 59^{\circ} \mathrm{C}$ for $30 \mathrm{sec} ; 72^{\circ} \mathrm{C}$ for $\left.1.5 \mathrm{~min}\right) ; 60^{\circ} \mathrm{C}$ for $60 \mathrm{~min}$ and held at $4^{\circ} \mathrm{C}$. PCR products were diluted 20 -fold prior to being run by capillary electrophoresis using an ABI 3730XL genetic analyzer (Applied Biosystems; Thermo Fisher Scientific, Inc., Waltham, MA, USA). Raw data were analyzed using GeneMapper, version 4.0 (Applied Biosystems; Thermo Fisher Scientific, Inc.) and height/area data for all specific peaks were exported into an excel file. The sample/competitive (S/C) peak ratio was calculated for the two target segments and three reference segments. The reference segments were screened and selected at three loci of POLR2A, POP1, and RPP14 as described previously (25). The $\mathrm{S} / \mathrm{C}$ ratio for each target fragment was first normalized based on three reference segments, respectively. The three normalized $\mathrm{S} / \mathrm{C}$ ratios were further normalized to the median value in all samples for each reference segment, respectively, and then the mean was calculated. If one of the three normalized $\mathrm{S} / \mathrm{C}$ ratios deviated $>25 \%$ from the mean of the other two, it was excluded from further analysis.

Statistical analysis. Statistical analyses were performed using SPSS 17.0 software (SPSS, Inc., Chicago, IL, USA). The distribution of FCGR3B copy number in subgroups was compared using the $\chi^{2}$ test. $\mathrm{P}<0.05$ was considered to indicate a statistically significant difference. The association between the copy number of FCGR3B and the risk of developing LN was investigated using logistic regression analysis-effects on risk being estimated by odds ratios (ORs) with $95 \%$ confidence intervals. Subsequently, the $\chi^{2}$ test or Fisher's exact probabilities were used to determine the association between FCGE3B copy number and the clinical phenotypes of LN.

\section{Results}

Baseline characteristics. The LN cohort comprised 130 females and 12 males with a female to male ratio of 10.83:1. The disease duration was $56.3 \pm 47.8$ months. The 328 healthy subjects contained 298 females and 30 males, and the female to male ratio was 9.93:1. Other clinical characteristics of $\mathrm{LN}$ at the time of biopsy are presented in Table II.

Distribution of FCGR3B copy number. The present study successfully acquired the copy numbers of $142 \mathrm{LN}$ patients and 328 controls. The copy numbers of FCGR3B in LN and healthy controls ranged from 1-4. The percentage of Henan healthy subjects with FCGR3B low copy number $(<2)$ was $8.5 \%$, whereas the percentage of FCGR3B high copy number (>2) was $24.4 \%$. The distribution of FCGR3B copy number was significantly different between $\mathrm{LN}$ and healthy control subjects $(\mathrm{P}=0.031$; Fig. 1$)$.

Association of LN susceptibility with FCGR3B low copy number. The present study examined whether the presence of a low copy number $(<2)$ or high copy number $(>2)$ was different between LN and healthy control subjects. As presented in Fig. 2A, the low copy number of FCGR3B was significantly 
Table I. Primers for different segments of FCGR3B.

\begin{tabular}{lll}
\hline Segments & \multicolumn{1}{c}{ Forward primer $\left(5^{\prime}-3^{\prime}\right)$} & \multicolumn{1}{c}{ Reverse primer $\left(5^{\prime}-3^{\prime}\right)$} \\
\hline FCGR3B-1 & CCATTTCCCGACCATGACCTC & CTACCAGTCCCGCCCTTCG \\
FCGR3B-2 & GCCCAGAGATAAGGGTGTCTTCC & AAGTACAGAACAAACCCTGTGTCACTG
\end{tabular}

FCGR3B, Fc $\gamma$ receptors 3B.

enriched in $\mathrm{LN}(\mathrm{P}=0.042)$. However, the high copy number exhibited no significant difference between LN and healthy control subjects ( $\mathrm{P}>0.05$; Fig. 2B).

Furthermore, the present study investigated whether FCGR3B CNVs were associated with a susceptibility to LN using logistic regression analysis. As presented in Table III, the high copy number $(>2)$ of FCGR3B was not associated with LN susceptibility (OR=1.152; 95\% confidence intervals, 0.711-1.866; $\mathrm{P}=0.565)$, however, the low copy number $(<2)$ was a risk factor for $\mathrm{LN}(\mathrm{OR}=2.059 ; 95 \%$ confidence intervals, 1.081-3.921; $\mathrm{P}=0.028)$.

Association of FCGR3B CNVs and clinical phenotypes of LN. Copy number frequencies were compared among LN patients stratified by each clinical characteristic. Firstly, the LN patients were classified to proliferative LN (types III and IV) and non-proliferative LN (types II and V). However, no association was observed between the FCGR3B CNVs and pathological type ( $\mathrm{P}=0.657$; Table IV). In addition, associations between SLEDAI, AI, CI and proteinuria and the number of FCGR3B CNVs was assessed, however no significant difference was observed ( $\mathrm{P}>0.05$; data not shown).

\section{Discussion}

FCGR3B, which is associated with immune complex clearance, is a member of the $\mathrm{Fc} \gamma$ receptor family, and is primarily expressed on human neutrophils (26). Previous studies regarded FCGR3B $\mathrm{CNV}$ as a risk factor for a range of autoimmune diseases, including rheumatoid arthritis and SLE (11-15,27). A copy number $<2$ of FCGR3B has emerged as a susceptibility factor in Caucasian patients with SLE. However, the CNV of FCGR3B varied between different geographic regions, making it difficult to extrapolate findings from one center to another. Studies into the copy number of the FCGR3B gene are scarce in China, specifically in the Henan province located in central China. In the current study, the association between CNVs of FCGR3B and diagnosis of LN in the Henan population in China was assessed.

A previous study demonstrated that FCGR3B CNV profiles were significantly different among ethnic groups (28). The frequencies of FCGR3B low copy number $(<2)$ and high copy number $(>2)$ in the Henan population are 8.5 and $24.4 \%$, respectively, which are significantly higher than that of Caucasian populations (3.8-7.4 and 8.8-12\%, respectively) $(28,29)$. This suggests that there are ethnical variations of FCGR3B CNV.

The current study is, to the best of our knowledge, the first to demonstrate that a low copy number of FCGR3B is a risk factor for $\mathrm{LN}$ in the Henan population. The association between a low copy number of FCGR3B and LN is in accordance with
Table II. Clinical characteristics of lupus nephritis.

\begin{tabular}{lc}
\hline Characteristic & Result \\
\hline Malar rash (\%) & 46.5 \\
Photosensitivity (\%) & 16.3 \\
Oral ulcer (\%) & 22.5 \\
Alopecia (\%) & 28.2 \\
Fever (\%) & 49.3 \\
Vasculitis (\%) & 11.3 \\
Arthritis (\%) & 45.1 \\
Serositis (\%) & 21.8 \\
Antinuclear antibodies (\%) & 96.8 \\
Anti-dsDNA antibodies (\%) & 60.6 \\
Low complement levels (\%) & 67.6 \\
Proteinuria, mean \pm SD (g/24 h) & $4.37 \pm 4.37$ \\
SLEDAI, mean \pm SD & $10.00 \pm 7.07$ \\
AI, mean \pm SD & $5.47 \pm 2.99$ \\
CI, mean \pm SD & $2.01 \pm 2.27$ \\
\hline
\end{tabular}

SD, standard deviation; SLEDAI, systemic lupus erythematosis disease activity index; AI, activity index; CI, chronic index.

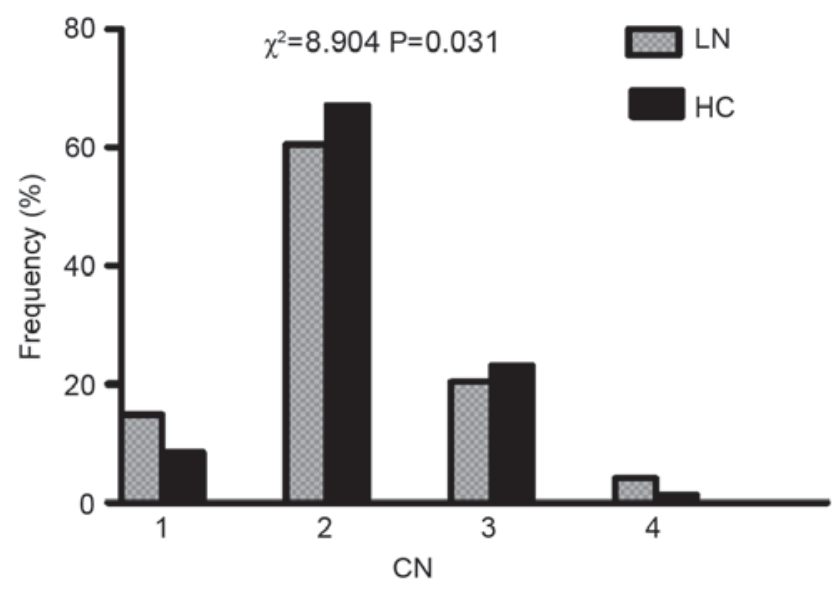

Figure 1. Distribution of FCGR3B CN in subgroups. The frequencies of different $\mathrm{CN}$ in subgroups were compared using the $\chi^{2}$ test. FCGR3B, Fc $\gamma$ receptors $3 \mathrm{~B}$; $\mathrm{LN}$, lupus nephritis; $\mathrm{HC}$, healthy controls; $\mathrm{CN}$, copy number.

studies in Afro-Caribbean and Caucasian populations (11-15) and is consistent with Chen et al's (8) and Niederer et al's (28) studies of Chinese populations. Furthermore, one previously published meta-analysis indicated that a low copy number 
A

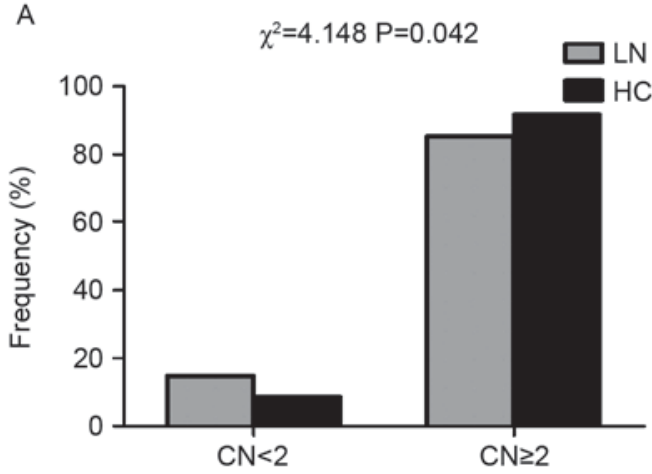

B

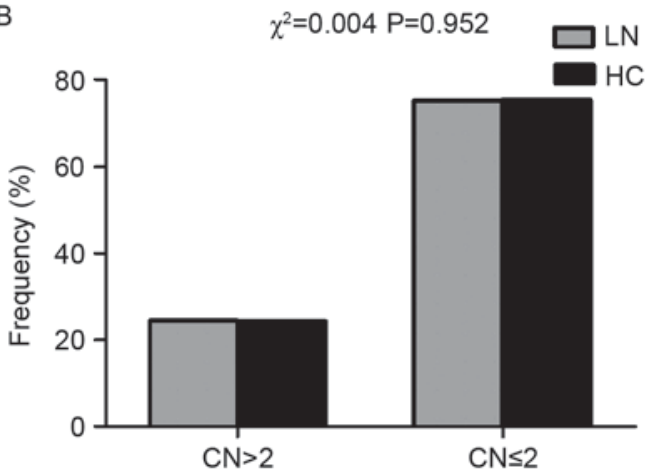

Figure 2. Low $\mathrm{CN}(<2)$ and high $\mathrm{CN}(>2)$ in LN patients and HC. (A) Bar chart demonstrating the distinction of FCGR3B low copy number $(<2)$ frequency between LN and HC. The CN $<2$ was significantly enriched in LN. (B) Bar chart demonstrating the frequency of FCGR3B high copy number ( $>2)$ in LN and HC. No significant difference was observed in the distribution of high CN in subgroups. LN, lupus nephritis; HC, healthy control; FCGR3B, Fc $\gamma$ receptors 3B; $\mathrm{CN}$, copy number.

Table III. Influence of FCGR3B gene CN on susceptibility to LN.

\begin{tabular}{|c|c|c|c|c|c|}
\hline FCGR3B CN & LN, n (total) & $\mathrm{HC}, \mathrm{n}$ (total) & P-value & $\mathrm{OR}^{\mathrm{a}}$ & $95 \% \mathrm{CI}$ \\
\hline$=2$ & 86 (142) & $220(328)$ & - & 1 & - \\
\hline Low, $<2$ & $21(142)$ & $28(328)$ & $0.028^{\mathrm{b}}$ & 2.059 & $1.081-3.921$ \\
\hline High, $>2$ & 35 (142) & $80(328)$ & 0.565 & 1.152 & $0.711-1.866$ \\
\hline
\end{tabular}

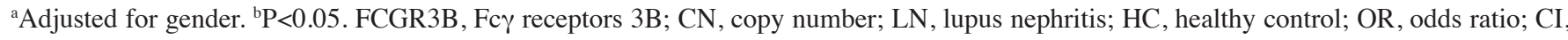
confidence intervals.

Table IV. Association of FCGR3B CN and pathological types of LN.

\begin{tabular}{|c|c|c|c|c|c|}
\hline \multirow[b]{2}{*}{ Pathological type } & \multicolumn{4}{|c|}{ FCGR3B CN } & \multirow[b]{2}{*}{ Total } \\
\hline & 1 & 2 & 3 & 4 & \\
\hline PLN, n & 13 & 49 & 17 & 2 & 81 \\
\hline NPLN, n & 8 & 37 & 12 & 4 & 61 \\
\hline Total & 21 & 86 & 29 & 6 & 142 \\
\hline
\end{tabular}

$\chi^{2}=1.609, \mathrm{P}=0.657 . \mathrm{FCGR} 3 \mathrm{~B}, \mathrm{Fc} \gamma$ receptors $3 \mathrm{~B} ; \mathrm{CN}$, copy number; LN, lupus nephritis; PLN, proliferative LN; NPLN, Non-PLN.

of FCGR3B was a risk factor for LN (30), suggesting that there is a positive association between low copy number of FCGR3B and a risk of developing LN. In contrast to the findings of the present study, no association between $\mathrm{LN}$ with FCGR3B CNVs was observed in southeastern and northern Chinese populations $(11,31,32)$. This discrepancy suggests that there may be regional variations. However, the sample size, experimental methodology and disease heterogeneity may also contribute to the difference, and the exact pathogenesis of the effect of low copy number on LN remains unknown. A previous study by Willcocks et al (11) demonstrated that in a family with FCGR3B-deficiency and the normal population, FCGR3B CNVs exhibit a gene dosage effect on protein levels of FCGR3B in serum and this is associated with neutrophil uptake of immune complexes. Reduced FCGR3B expression is thus, likely to contribute to the impaired clearance of immune complexes, which is a feature of LN, explaining the association between low FCGR3B CN and LN.

A study by Nossent et al (15) demonstrated that a low copy number of FCGR3B was associated with SLEDAI, increased levels of anti-dsDNA antibody and ribosomal P. Furthermore, Chen et al (8) revealed that FCGR3B low copy number genotypes were significantly enriched in SLE patients with ulcer and nephritis. However, the present study failed to find any association between FCGR3B CNV and the clinical features of LN. It has been demonstrated that patients with SLE from East Asia have more severe clinical manifestations, such as proliferative nephritis $(33,34)$. Therefore, it is to be expected that different ethnic groups may have different genetic susceptibility to SLE. This has been supported by various previous studies (28,35-37).

In conclusion, the present study was, to the best of our knowledge, the first to demonstrate that a low copy number of FCGR3B increases the risk of LN in the Henan population of China. However, the sample size is relatively small and although the AccuCopy method used in the current study has been validated by a number of studies $(25,38)$, accurately measuring $\mathrm{CNV}$ remains a technical challenge, which requires further investigation.

\section{Acknowledgements}

The present study was supported by grants from National Key Technology R\&D Program (grant no. 2011BAI10B04) and National Basic Research Program of China 973 Program (grant no. 2012CB517606). The authors of the current study 
would like to thank Dr Lijuan Zhang, Dr Yongsheng Lei and Dr Weixia Liu for their help in collecting the blood samples and clinical data of patients and Dr Linlin Li from the Department of Biostatistics, College of Public Health, Zhengzhou University for helping to analyze the data.

\section{References}

1. Yu C, Gershwin ME and Chang C: Diagnostic criteria for systemic lupus erythematosus: A critical review. J Autoimmun 48-49: 10-13, 2014.

2. Choi J, Kim ST and Craft J: The pathogenesis of systemic lupus erythematosus-an update. Curr Opin Immunol 24: 651-657, 2012

3. Redon R, Ishikawa S, Fitch KR, Feuk L, Perry GH, Andrews TD, Fiegler H, Shapero MH, Carson AR, Chen W, et al: Global variation in copy number in the human genome. Nature 444: 444-454, 2006.

4. Pacheco GV, Cruz DC, González Herrera LJ, Pérez Mendoza GJ, Adrián Amaro GI, Nakazawa Ueji YE and Angulo Ramirez AV: Copy number variation of TLR-7 gene and its association with the development of systemic lupus erythematosus in female patients from Yucatan Mexico. Genet Epigenet 6: 31-36, 2014.

5. Kim JH, Jung SH, Bae JS, Lee HS, Yim SH, Park SY, Bang SY, $\mathrm{Hu}$ HJ, Shin HD, Bae SC and Chung YJ: Deletion variants of RABGAP1L, 10q21.3, and C4 are associated with the risk of systemic lupus erythematosus in Korean women. Arthritis Rheum 65: 1055-1063, 2013.

6. Garcia-Ortiz H, Velázquez-Cruz R, Espinosa-Rosales F Jiménez-Morales S, Baca V and Orozco L: Association of TLR7 copy number variation with susceptibility to childhood-onset systemic lupus erythematosus in Mexican population. Ann Rheum Dis 69: 1861-1865, 2010.

7. McKinney C, Merriman ME, Chapman PT, Gow PJ,Harrison AA, Highton J, Jones PB, McLean L, O'Donnell JL, Pokorny V, et al: Evidence for an influence of chemokine ligand 3-like 1 (CCL3L1) gene copy number on susceptibility to rheumatoid arthritis. Ann Rheum Dis 67: 409-413, 2008.

8. Chen JY, Wang CM, Chang SW, Cheng CH, Wu YJ, Lin JC, Yang B, Ho $\mathrm{HH}$ and $\mathrm{Wu} \mathrm{J}$ : Association of FCGR3A and FCGR3B copy number variations with systemic lupus erythematosus and rheumatoid arthritis in Taiwanese patients. Arthritis Rheumatol 66: 3113-3121, 2014.

9. Colombo FR, Torrente Y, Casati R, Benti R, Corti S, Salani S, D'Angelo MG, DeLiso A, Scarlato G, Bresolin N and Gerundini P: Biodistribution studies of $99 \mathrm{mTc}$-labeled myoblasts in a murine model of muscular dystrophy. Nucl Med Biol 28: 935-940, 2001.

10. Nimmerjahn F and Ravetch JV: Fcgamma receptors: Old friends and new family members. Immunity 24: 19-28, 2006.

11. Willcocks LC, Lyons PA, Clatworthy MR, Robinson JI, Yang W, Newland SA, Plagnol V, McGovern NN, Condliffe AM, Chilvers ER, et al: Copy number of FCGR3B, which is associated with systemic lupus erythematosus, correlates with protein expression and immune complex uptake. J Exp Med 205: 1573-1582, 2008.

12. Fanciulli M, Norsworthy PJ, Petretto E, Dong $R$, Harper L, Kamesh L, Heward JM, Gough SC, de Smith A, Blakemore AI, et al: FCGR3B copy number variation is associated with susceptibility to systemic, but not organ-specific, autoimmunity. Nat Genet 39: 721-723, 2007.

13. Morris DL, Roberts AL, Witherden AS, Tarzi R, Barros P, Whittaker JC, Cook TH, Aitman TJ and Vyse TJ: Evidence for both copy number and allelic (NA1/NA2) risk at the FCGR3B locus in systemic lupus erythematosus. Eur J Hum Genet 18: $1027-1031,2010$

14. Molokhia M, Fanciulli M, Petretto E, Patrick AL, McKeigue P, Roberts AL, Vyse TJ and Aitman TJ: FCGR3B copy number variation is associated with systemic lupus erythematosus risk in Afro-Caribbeans. Rheumatology (Oxford) 50: 1206-1210, 2011.

15. Nossent JC, Becker-Merok A, Rischmueller M and Lester S: Susceptibility for lupus nephritis by low copy number of the FCGR3B gene is linked to increased levels of pathogenic autoantibodies. Autoimmune Dis 2013: 750814, 2013.

16. Nossent JC, Rischmueller M and Lester S: Low copy number of the $\mathrm{Fc}-\gamma$ receptor $3 \mathrm{~B}$ gene FCGR3B is a risk factor for primary Sjogren's syndrome. J Rheumatol 39: 2142-2147, 2012.
17. McKinney C, Broen JC, Vonk MC, Beretta L, Hesselstrand R, Hunzelmann N, Riemekasten G, Scorza R, Simeon CP, Fonollosa V, et al: Evidence that deletion at FCGR3B is a risk factor for systemic sclerosis. Genes Immun 13: 458-460, 2012.

18. Bertsias GK, Tektonidou M, Amoura Z, Aringer M, Bajema I, Berden JH, Boletis J, Cervera R, Dörner T, Doria A, et al: Joint European league against rheumatism and European renal Association-European dialysis and transplant association (EULAR/ERA-EDTA) recommendations for the management of adult and paediatric lupus nephritis. Ann Rheum Dis 71: 1771-1782, 2012.

19. Hochberg MC: Updating the American College of Rheumatology revised criteria for the classification of systemic lupus erythematosus. Arthritis Rheum 40: 1725, 1997.

20. Tan EM, Cohen AS, Fries JF, Masi AT, McShane DJ, Rothfield NF, Schaller JG, Talal N and Winchester RJ: The 1982 revised criteria for the classification of systemic lupus erythematosus. Arthritis Rheum 25: 1271-1277, 1982.

21. Dooley MA, Aranow C and Ginzler EM: Review of ACR renal criteria in systemic lupus erythematosus. Lupus 13: 857-860, 2004.

22. Weening JJ, D'Agati VD, Schwartz MM, Seshan SV, Alpers CE, Appel GB, Balow JE, Bruijn JA, Cook T, Ferrario F, et al: The classification of glomerulonephritis in systemic lupus erythematosus revisited. Kidney Int 65: 521-530, 2004

23. Austin HA III, Muenz LR, Joyce KM, Antonovych TT and Balow JE: Diffuse proliferative lupus nephritis: Identification of specific pathologic features affecting renal outcome. Kidney Int 25: 689-695, 1984

24. Gladman DD, Ibañez D and Urowitz MB: Systemic lupus erythematosus disease activity index 2000. J Rheumatol 29: 288-291, 2002.

25. Du R, Lu C, Jiang Z, Li S, Ma R, An H, Xu M, An Y, Xia Y, Jin $L$, et al: Efficient typing of copy number variations in a segmental duplication-mediated rearrangement hotspot using multiplex competitive amplification. J Hum Genet 57: 545-551, 2012.

26. Ravetch JV and Perussia B: Alternative membrane forms of Fc gamma RIII(CD16) on human natural killer cells and neutrophils. Cell type-specific expression of two genes that differ in single nucleotide substitutions. J Exp Med 170: 481-497, 1989.

27. Robinson JI, Carr IM, Cooper DL, Rashid LH, Martin SG, Emery P, Isaacs JD, Barton A; BRAGGSS, Wilson AG, et al: Confirmation of association of FCGR3B but not FCGR3A copy number with susceptibility to autoantibody positive rheumatoid arthritis. Hum Mutat 33: 741-749, 2012.

28. Niederer HA, Willcocks LC, Rayner TF, Yang W, Lau YL, Williams TN, Scott JA, Urban BC, Peshu N, Dunstan SJ, et al: Copy number, linkage disequilibrium and disease association in the FCGR locus. Hum Mol Genet 19: 3282-3294, 2010.

29. Hollox EJ, Detering JC and Dehnugara T: An integrated approach for measuring copy number variation at the FCGR3 (CD16) locus. Hum Mutat 30: 477-484, 2009.

30. Yuan J, Zhao D, Wu L, Xu X, Pang Y, Zhang J, Ma Y, Liu J and Wang J: FCGR3B copy number loss rather than gain is a risk factor for systemic lupus erythematous and lupus nephritis: A meta-analysis. Int J Rheum Dis 18: 392-397, 2015.

31. Lv J, Yang Y, Zhou X, Yu L, Li R, Hou P and Zhang H: FCGR3B copy number variation is not associated with lupus nephritis in a Chinese population. Lupus 19: 158-161, 2010.

32. Yang H, Zhou Q, Chen D, Jiang H, Mao Y and Chen J: The single nucleotide polymorphisms gene but not the copy number variation of Fcgr3B is associated with lupus nephritis in Chinese people. Lupus 19: 662-664, 2010.

33. Shayakul C, Ong-aj-yooth L, Chirawong P, Nimmannit S, Parichatikanond $\mathrm{P}$, Laohapand T, Vasuvattakul S, Vareesangthip K, Vanichakarn S, Malasit P, et al: Lupus nephritis in Thailand: Clinicopathologic findings and outcome in 569 patients. Am J Kidney Dis 26: 300-307, 1995.

34. Sisó A, Ramos-Casals M, Bové A,Brito-Zerón P, Soria N, Nardi N, Testi A, Perez-de-Lis M, Díaz-Lagares C, Darnell A, et al: Outcomes in biopsy-proven lupus nephritis: Evaluation of 190 white patients from a single center. Medicine (Baltimore) 89: 300-307, 2010

35. Mamtani M, Rovin B, Brey R, Camargo JF, Kulkarni H, Herrera M, Correa P, Holliday S, Anaya JM and Ahuja SK: CCL3L1 gene-containing segmental duplications and polymorphisms in CCR5 affect risk of systemic lupus erythaematosus. Ann Rheum Dis 67: 1076-1083, 2008. 
36. Kyogoku C, Dijstelbloem HM, Tsuchiya N, Hatta Y, Kato H, Yamaguchi A, Fukazawa T, Jansen MD, Hashimoto H, van de Winkel JG, et al: Fcgamma receptor gene polymorphisms in Japanese patients with systemic lupus erythematosus: Contribution of FCGR2B to genetic susceptibility. Arthritis Rheum 46: 1242-1254, 2002.

37. Li X, Wu J, Carter RH, Edberg JC, Su K, Cooper GS and Kimberly RP: A novel polymorphism in the Fcgamma receptor IIB (CD32B) transmembrane region alters receptor signaling. Arthritis Rheum 48: 3242-3252, 2003.
38. Cai G, Xia Q, Fan D, Li X, Ding N, Hu Y, Yang X, Liu L, Xin L, Wang L, et al: Association between DEFB103 gene copy number variation and ankylosing spondylitis: A case-control study. Tissue Antigens 86: 195-198, 2015. 